\title{
An Improvement of Coherence and Validity between CLD and SFD of System Dynamics
}

\author{
Jae Un Jung ${ }^{*}$ Hyun Soo Kim ${ }^{* \star}$ \\ BK21Plus Groups, Dong-A Univerisity ${ }^{*}$ \\ Dept. of Management Information Systems, Dong-A Univerisity ${ }^{*}$ \\ 시스템 다이내믹스의 $\mathrm{CLD}$ 와 $\mathrm{SFD}$ 의 \\ 일관성 및 타당성 개선에 관한 연구 \\ 정재운, 김현수 ${ }^{*}$ \\ 동아대학교 BK21PLUS총괄사업단, 동아대학교 경영정보학과"
}

\begin{abstract}
System Dynamics(SD) is one of the complexity theories that has attracted attention as a computer-aided simulation methodology to analyze a dynamic problem and to develop a policy(strategy) in social science. Though there are properly unproven cases in research models which were developed in various fields by SD methodology during the last five decades, they are utilized as models to represent SD sub-theories. For this reason, this study targeted the population dynamics model which was frequently utilized to explain SD fundamentals and it proved errors of reasoning a structure of the existing causal and dominant feedback loop. Consequently, we presented a strategy to strengthen the coherence between CLD(causal loop diagram) and SFD(stocks-and-flows diagram) for improving validity of the existing model. The findings of this study contribute to the advancement of the existing SD and to the reinforcement of validation for policy research models of SD.
\end{abstract}

Key Words : Causal Loop Diagram, Coherence, Stocks-and-Flows Diagram, System Dynamics, Validity

요 약 시스템 다이내믹스(SD)는 복잡계 이론 중의 하나로서 사회과학 분야에서 동태적 문제의 분석 및 정책(전략) 개발을 위한 컴퓨터 기반의 시뮬레이션 연구방법론으로 많은 관심을 받아 왔다. 하지만 지난 50 여 년간 다양한 분야 에서 이 방법론으로 만들어진 모형 중에는 아직 검증이 제대로 되지 않은 채 시스템다이내믹스의 구성이론을 대표하 는 모형으로 활용되는 사례들이 있다. 이에 본 연구에서는 $\mathrm{SD}$ 의 이론을 설명하는 데 자주 활용되는 인구 동태학 모 형을 대상으로 인과적 피드백 구조와 지배적 피드백 루프의 추론 오류를 증명하고, 인과지도(causal loop diagram)와 저량-유량 다이어그램(stocks-and-flows diagram) 간의 일관성 강화 전략을 통해 기존 모형의 타당성을 개선하였다. 본 연구의 결과는 기존 시스템다이내믹스의 이론적 발전과 시스템다이내믹스를 활용한 정책 연구모형의 타당성 강화에 기여한다.

주제어 : 시스템 다이내믹스, 일관성, 인과지도, 저량-유량 다이어그램, 타당성

\footnotetext{
* 이 논문은 2011년도 정부(교육부)의 재원으로 한국연구재단의 지원을 받아 연구되었음(NRF-2011-35C-B00111)

Received 19 April 2014, Revised 28 May 2014

Accepted 20 June 2014

Corresponding Author: Hyun Soo Kim(Dong-A University)

Email: hskim@dau.ac.kr

ISSN: 1738-1916
} 


\section{Introduction}

In social science, questionnaire-based empirical methodologies are important but not sufficient for dynamic issues. For this reason, system dynamics(SD) which is one of the complexity theories has been a good alternative in areas where empirical studies cannot cover. In 1960s, the fundamentals of SD started to be formed by Industry Dynamics and Urban Dynamics[1,2]. SD focuses on modeling a closed system which consists of causality in a dynamic problem and it reproduces dynamics(phenomenon) in the real world by computer simulation. In other words, this approach enables a(n) efficient design and analysis of a dynamic model, so it provisions another point of view to draw a policy or strategy as a solution by simulating future dynamics. Such an advantage is enough to stimulate new challenges of social scientists and actually it has resulted in lots of SD applications including Business Dynamics in various domains[3].

However having been utilized in parts of social science for more than 50 years, a few SD models exposes weak points on verifying objective validity because empirical or logical evaluation has a tendency to be overlooked. It makes researchers reluctant to use the SD methodology for their robust findings even though they know that the approach is something new and better at social dynamic problem.

For this issue, this study aims to improve the existing sub-theory and reference model by reverifying the population dynamics model which is a representative model to explain the heart of the SD theory. Our findings are significant to invigorate a scientific discourse for theoretical improvements and wide applications of SD.

In section 2, characteristics and arguable issues of SD are reviewed and in section 3, validity of the existing theory model is re-proved. In section 4, an improvement strategy of the SD model is presented by reinforcing coherence between CLD(causal loop diagram) and SFD(stocks-and-flows diagram).

\section{Literature Review}

\subsection{System Dynamics and Policy}

\subsubsection{Computer-Aided Analysis and Design}

Even if a policy for a social issue is well-designed, results of the implemented policy can turn out against policy maker's expectations because there is a subtle difference in the real world from the viewpoint of resource, time, resistance, etc. Therefore different effects on the same policy should be fully analyzed. In this regard, SD provisions an approach of computer-aided simulation for a dynamic diversity which arises from the same problem structure as shown in [Fig. 1].

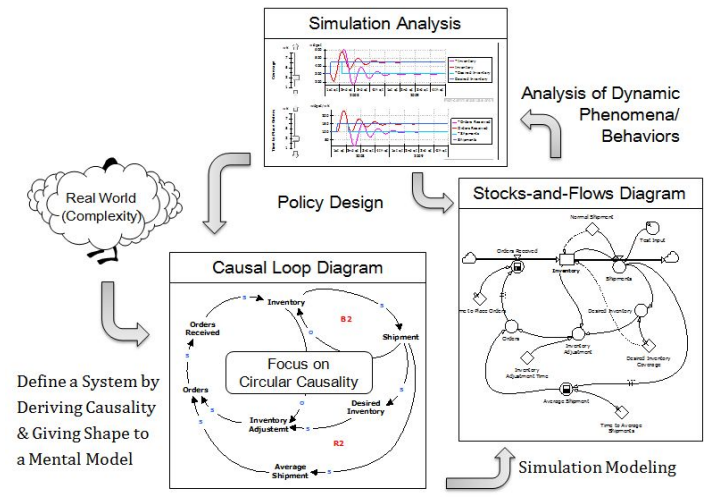

[Fig. 1] SD Approaches for Dynamic Problems Source: Inventory Simulation in Powersim Studio 8 Samples

\subsubsection{Key Tools of System Dynamics}

The heart of the SD methodology is the feedback(system) thinking that provisions a viewpoint to define circular causality called closed system[4]. On the basis of the philosophy, two major tools are utilized for modeling a dynamic problem.

The first is the CLD(causal loop diagram) which is drawn with fractions of causality in a(n) complex or abstract problem. It is good at deriving and 
concretizing a feedback loop as a conceptual model[5].

The second is the SFD(stocks-and-flows diagram) which contains mathematical models(calculus formulae) for simulating dynamics of the research model. The both tools are interconnected so, according to the need, they can be utilized in consecutive or reverse order[6].

\subsection{Arguable Issues}

\subsubsection{CLD Notation}

Most of arguable issues on SD are related to the CLD notation. The notation basically consists of variable, arrow, polarity. A variable is a factor which composes a problem and an arrow presents a causal direction between variables. So, these two define a problem structure. Polarity is marked on the head of an arrow as $+(\mathrm{S})$ or $-(\mathrm{O})$. For instance, if $\mathrm{A}$ increases (decreases) and B increases(decreases), then the causal polarity between $\mathrm{A}$ and $\mathrm{B}$ is defined as +(positive) or $\mathrm{S}$ (same), but if A increases(decreases) and B decreases (increases), then the polarity is defined as -(negative) or O(opposite)[3,7].

Related to the polarity notation, in 1990s, [7] pointed out a logical flaw when causal links(arrows) were labeled with the $\mathrm{S}$ and $\mathrm{O}$ notation. Then, the study asserted the need to replace the notation with plus $(+)$ and minus(-) signs which mean "add to" and "subtract from" unlike the aforementioned. In 2000s, [8] explored expressional and logical limitations of CLD and [9] suggested additional symbols and marks including starting point $(\bullet)$ and conditions $(<,>$, =) of dynamics for rich expression of CLD.

\subsubsection{Representative but Questionable Models}

When a CLD is drawn from the incomplete or uncertain information of a problem, it is difficult to find an obvious feedback loop from unconnected fractions of causality. Then, partially presuming causality on the open interval of an unclosed loop is required for a complete feedback loop but if there is no strict verification, such a part can weaken validity of a whole research model. Related to this issue, [8] validated errors of the existing SD models noted for population dynamics and sales dynamics with empirical data and conditional proofs.

On the other hand, when the population dynamics is mentioned, sigmoid curve is frequently utilized because it expresses the typical ecological phenomenon called S-shaped growth. According to the SD theory[3,5,6], the growth curve is a result of interaction between positive(+) and negative( $\left.{ }^{-}\right)$feedback loops so, before and after the turning point of the curve, there is a different dominant feedback loop as shown in [Fig. 2].

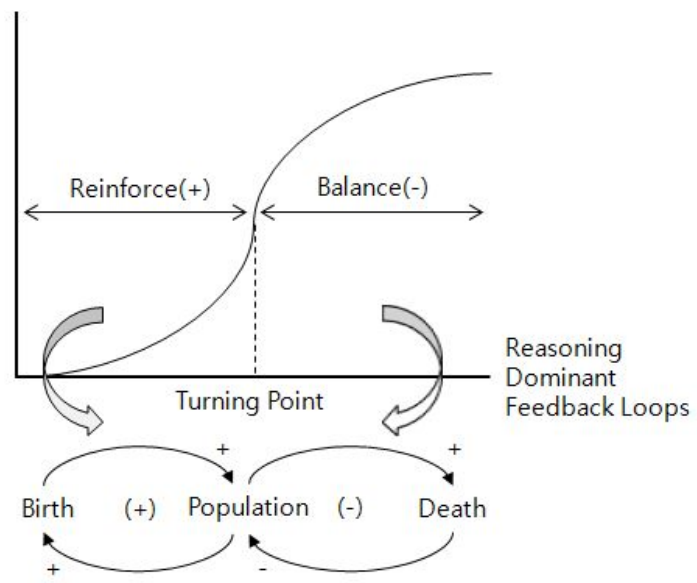

[Fig. 2] Reasoning Dominant Feedback Loops Source: Kim(2006). System Thinking, p.162, Fig. 17, edited.

However the reasoning principle as mentioned above is questionable because the graph just grows in one direction. That means dynamics of the curve can be generated by reinforcement(positive) feedback loop, not balance(negative) feedback loop. Also, the CLD(lower part of [Fig. 2]) can not explain realistic dynamics of population. According to the CLD, population should increase if the number of deaths decreases but not actually. In this sense, there seems some thing wrong with [Fig. 2]. If there is a theoretical flaw of the model, so if it can be proven by this study, it is enough to 
raise a doubt about validity of the existing SD model and theory. In order to solve the doubt, simple but important proofs are conducted as follows.

\section{Simple Proofs}

\subsection{Geometrical Proof}

For re-evaluation of reasoning a dominant feedback loop from the sigmoid curve in [Fig. 2], it is required to prove whether the curve can present dynamics of positive and negative feedback loops, whether there is a shift between different dominant feedback loops. So, we first generated the sigmoid curve of [Fig. 3] using equation (1) and analyzed each variation $\left(t_{n}-t_{n-1}\right)$ during time $(\mathrm{t}$, interval $=1)$ as shown in $\langle$ Table 1$\rangle$.

$$
P(t)=\frac{1}{1+e^{-t}}
$$

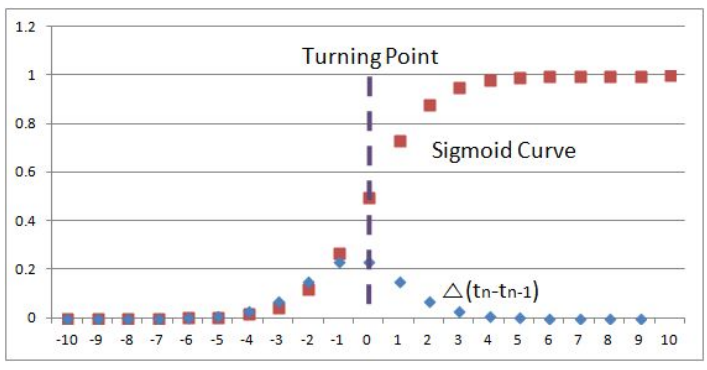

[Fig. 3] Geometric Analysis of Sigmoid Curve

〈Table 1〉 Instantaneous Rate of Change $\left(t_{n}-t_{n-1}\right)$

\begin{tabular}{|c|c|c|c|}
\hline Time $(\mathrm{t})$ & Variation $(\triangle)$ & Time $(\mathrm{t})$ & Variation $(\triangle)$ \\
& & 0 & 0.2311 \\
\hline-10 & 0.0001 & 1 & 0.1497 \\
\hline-9 & 0.0002 & 2 & 0.0718 \\
\hline-7 & 0.0006 & 3 & 0.0294 \\
\hline-6 & 0.0016 & 4 & 0.0113 \\
\hline-5 & 0.0042 & 5 & 0.0042 \\
\hline-4 & 0.0113 & 6 & 0.0016 \\
\hline-3 & 0.0294 & 7 & 0.0006 \\
\hline-2 & 0.0718 & 8 & 0.0002 \\
\hline-1 & 0.1497 & 9 & 0.0001 \\
\hline 0 & 0.2311 & 10 & \\
\hline
\end{tabular}

During the period of $-10 \leq t \leq 0$, instantaneous rate of change(differential coefficient) steadily increased. This pattern resembled that of the reinforcement(+) feedback loop.

After $\mathrm{t}=0$ (turning point of the growth curve), differential coefficients kept decreasing until $\mathrm{t}=10$ but the value was still larger than 0(refer to $\langle$ Table1 $\rangle$ ). This means that the curve kept growing until $t=10$. Such a pattern is also found from the reinforcement $(+)$ feedback loop. If there is a negative(-) dominant feedback loop during the period, a pattern like a(n) fluctuation or oscillation should be observed but not.

For this reason, it is difficult to conclude that there is a negative feedback loop on the graph. That means any shift of dominant feedback loops is not satisfied.

\subsection{Conditional Proofs}

For validation of an additional flaw in [Fig. 2], equation (2) was considered with the following three conditions; $\mathrm{B}_{\mathrm{r}}($ birth rate $)=\mathrm{D}_{\mathrm{r}}($ death rate $), \mathrm{B}_{\mathrm{r}}>\mathrm{D}_{\mathrm{r}}, \mathrm{B}_{\mathrm{r}}<\mathrm{D}_{\mathrm{r}}$.

$$
P_{t}=P_{t-1}+B_{t}-D_{t}
$$

( $\mathrm{t}=$ time, $\mathrm{P}=$ population, $\mathrm{B}=$ birth, $\mathrm{D}=$ death)

\subsubsection{Condition $1\left(\mathrm{~B}_{\mathrm{r}}=\mathrm{D}_{\mathrm{r}}\right)$}

For analysis of the population dynamics CLD in the condition of $\mathrm{B}_{\mathrm{r}}=\mathrm{D}_{\mathrm{r}}$, values of $\mathrm{P}_{0}$ (initial population), $\mathrm{B}_{1}$ and $\mathrm{D}_{\mathrm{r}}$ were set at $1,000,10 \%, 10 \%$ in order.

〈Table 2〉 Dynamics in the Condition $1\left(B_{r}=D_{r}\right)$

\begin{tabular}{|c|c|c|c|c|}
\hline Time $(\mathrm{t})$ & Birth & Death & Variation $(\triangle)$ & Population \\
\hline 0 & - & - & - & 1,000 \\
\hline 1 & 100 & 100 & 0 & 1,000 \\
\hline 2 & 100 & 100 & 0 & 1,000 \\
\hline 3 & 100 & 100 & 0 & 1,000 \\
\hline 4 & 100 & 100 & 0 & 1,000 \\
\hline 5 & 100 & 100 & 0 & 1,000 \\
\hline 6 & 100 & 100 & 0 & 1,000 \\
\hline 7 & 100 & 100 & 0 & 1,000 \\
\hline 8 & 100 & 100 & 0 & 1,000 \\
\hline 9 & 100 & 100 & 0 & 1,000 \\
\hline 10 & 100 & 100 & 0 & 1,000 \\
\hline
\end{tabular}


Then, any variation was not observed as shown in $<$ Table 2> which kept the same values like a static model. Under this condition, any circular causality (feedback loop) could not be inferred as shown in [Fig. 4], so the existing CLD in [Fig. 2] is not satisfied.

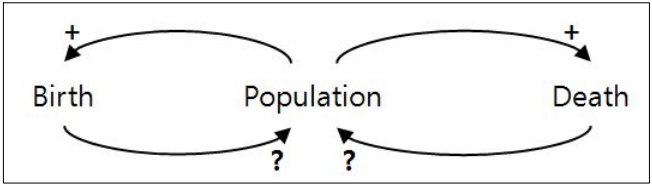

[Fig. 4] CLD in the Condition 1

\subsubsection{Condition2 $\left(\mathrm{B}_{\mathrm{r}}>\mathrm{D}_{\mathrm{r}}\right)$}

In the condition of $\mathrm{B}_{\mathrm{r}}>\mathrm{D}_{\mathrm{r}}$, values of $\mathrm{P}_{0}, \mathrm{~B}_{\mathrm{r}}$ and $\mathrm{D}_{\mathrm{r}}$ were set at 1,000, 10\%, $7 \%$ in order. Calculated results were rounded off to the nearest integer. Then, all the numbers of 'birth', 'death' and 'population' increased as shown in $\langle$ Table 3$\rangle$. That meant the values of all variables changed in the same direction, so causality between them could be defined as shown in [Fig. 5]. This result is different from the CLD of [Fig. 2] in the part of R2.

$\left\langle\right.$ Table 3 〉 Dynamics in the Condition2 $\left.\left(B_{r}\right\rangle D_{r}\right)$

\begin{tabular}{|c|c|c|c|c|}
\hline Time $(\mathrm{t})$ & Birth & Death & Variation & Population \\
\hline 0 & - & - & - & 1,000 \\
\hline 1 & 100 & 70 & 30 & 1,030 \\
\hline 2 & 103 & 72 & 31 & 1,061 \\
\hline 3 & 106 & 74 & 32 & 1,093 \\
\hline 4 & 109 & 76 & 33 & 1,126 \\
\hline 5 & 113 & 79 & 34 & 1,159 \\
\hline 6 & 116 & 81 & 35 & 1,194 \\
\hline 7 & 119 & 84 & 36 & 1,230 \\
\hline 8 & 123 & 86 & 37 & 1,267 \\
\hline 9 & 127 & 89 & 38 & 1,305 \\
\hline 10 & 130 & 91 & 39 & 1,344 \\
\hline
\end{tabular}

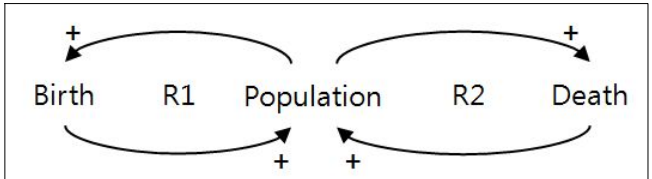

[Fig. 5] CLD in the Condition 2

\subsubsection{Condition3 $\left(B_{r}\left\langle D_{r}\right)\right.$}

In the condition of $\mathrm{B}_{\mathrm{r}}<\mathrm{D}_{\mathrm{r}}$, values of $\mathrm{P}_{0}, \mathrm{~B}_{\mathrm{r}}$ and $\mathrm{D}_{\mathrm{r}}$ were set at $1,000,7 \%, 10 \%$ in order. Calculated numbers were rounded off to the nearest integer. Then, all the numbers of 'birth', 'death' and 'population' decreased as shown in $\langle$ Table 4$\rangle$. That meant the values of all variables changed in the same direction, so causality between them could be defined as shown in [Fig. 6]. It is also the same with [Fig. 5] but different from the CLD of [Fig. 2].

〈Table 4〉 Dynamics in the Condition3 $\left(B_{r}\left\langle D_{r}\right)\right.$

\begin{tabular}{|c|c|c|c|c|}
\hline Time(t) & Birth & Death & Variation & Population \\
\hline 0 & - & - & - & 1,000 \\
\hline 1 & 70 & 100 & -30 & 970 \\
\hline 2 & 68 & 97 & -29 & 941 \\
\hline 3 & 66 & 94 & -28 & 913 \\
\hline 4 & 64 & 91 & -27 & 885 \\
\hline 5 & 62 & 89 & -27 & 859 \\
\hline 6 & 60 & 86 & -26 & 833 \\
\hline 7 & 58 & 83 & -25 & 808 \\
\hline 8 & 57 & 81 & -24 & 784 \\
\hline 9 & 55 & 78 & -24 & 760 \\
\hline 10 & 53 & 76 & -23 & 737 \\
\hline
\end{tabular}

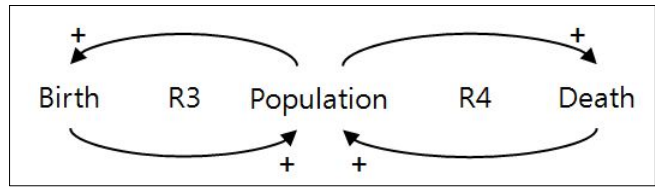

[Fig. 6] CLD in the Condition 3

From the results so far proved, our conditional proofs which detected the logical incorrectness from the population CLD in [Fig. 2] hold true in terms of dynamics(phenomenon) from the tables, but not in terms of structure. Over time, the values of 'population' and 'death' in <Table 3> changed only in the increase(same) direction and those in <Table $4>$ moved only in the decrease(same) direction, so each dynamics is possible to be defined as a reinforcement (+) feedback loop. But this definition is incorrect since death results in a decrease in population size. It does not mean that the causality between 'death' and 
'population' forms a negative feedback loop because any negative causality between both variables was not observed as aforementioned. There seemed to be a feedback loop but any polarity of the feedback loop was not obviously revealed in this approach. So, it is impossible to define the dynamics between 'death' and 'population' as an obvious feedback loop, as shown in [Fig. 7].

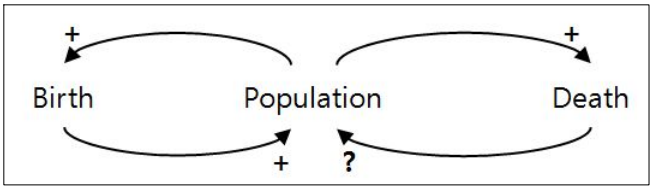

[Fig. 7] Modified CLD

So far, this section has described the flaws of [Fig. 2]. There was no negative feedback loop both on the sigmoid curve and the population dynamics CLD, so it was impossible to reason the shift of dominant feedback loops from the graph and the CLD unlike the conventional claim.

In the following section 4, a strategy for improving the existing population dynamics model is presented in terms of coherence between CLD and SFD.

\section{Coherence between CLD and SFD}

\subsection{Structural Coherence}

As mentioned in the section 2.1.2, SFD is the simulation model of CLD so it is interconnected and ultimately consistent with CLD. In order to prove this in theory, the population dynamics SFD was developed as shown in [Fig. 8].

In the SFD, 'birth' and 'death' of the CLD were defined as flow variables(rates) and 'population' of the CLD was defined as a stock variable. For example, 'birth' is an inflow(increase) of the population and 'death' is an outflow(decrease) of the population as follows.

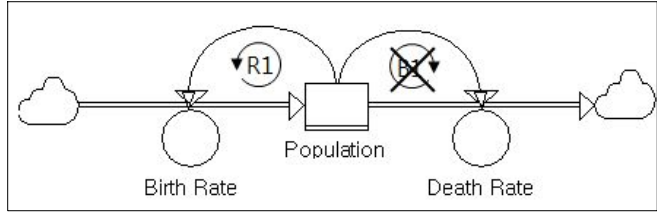

[Fig. 8] SFD of the Population Dynamics

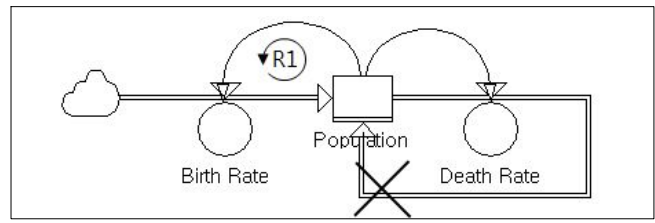

[Fig. 9] Flawed Feedback Loop in SFD

In [Fig. 8], there seem to be two feedback loops but there is no feedback loop between 'population' and 'death(rate)'. If there is a feedback loop between 'population' and 'death(rate)', 'death(rate)' should be the inflow and outflow of 'population'. But it is contradictory when 'death(rate)' is the inflow of 'population like 'birth(rate)' as shown in [Fig. 9]. It is logically not satisfied.

The result shows the validity of [Fig. 7] by structural coherence between [Fig. 7] and [Fig. 8]. It also implies that coherence between CLD and SFD can be applied to correct an error on either side of CLD and SFD.

\subsection{Improvement of the Existing Model}

In this section, the existing CLD in [Fig. 2] is improved by a strategy for maintaining coherence between CLD and SFD. Related to this, first, the structure of [Fig. 8] was modified with equation (3) and (4) as shown in [Fig. 10]. This model is similar with [6].

$$
\begin{aligned}
P_{t} & =P_{t-1}+V_{t} \quad(\mathrm{~V}=\text { variation rate }) \\
V_{t} & =B_{t}-D_{t}
\end{aligned}
$$

The result of equation (3) and (4) is the same with 
equation (2), so there is no difference between [Fig. 8] and [Fig. 10] except the structural form.

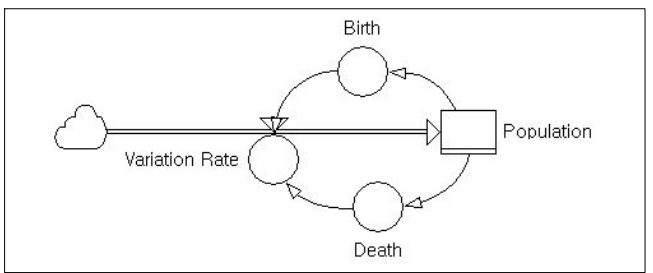

[Fig. 10] Modified SFD

In [Fig. 10], two complete feedback loops are observed in the 'population'-' birth $^{-}{ }^{\prime}$ variation rate' loop and the 'population'-'death' ${ }^{-}$'variation rate' loop unlike [Fig. 8] or [Fig. 9] which has only one. From the modified SFD, we get an insight to draw an advanced CLD for population dynamics in terms of coherence between CLD and SFD. So, population dynamics were simulated in the same conditions of the section 3(time unit: year) and the existing CLD was improved as follows.

\subsubsection{Condition $1\left(\mathrm{~B}_{\mathrm{r}}=\mathrm{D}_{\mathrm{r}}\right)$}

Under the condition of $\mathrm{B}_{\mathrm{r}}=\mathrm{D}_{\mathrm{r}}$, there was no change of all variables(population, birth, death, variation rate) in the simulation result([Fig. 11]) that only initial values were kept like a static model. It is because the value of 'birth' was the same with 'death'. From this result, any circular causality could not be defined.

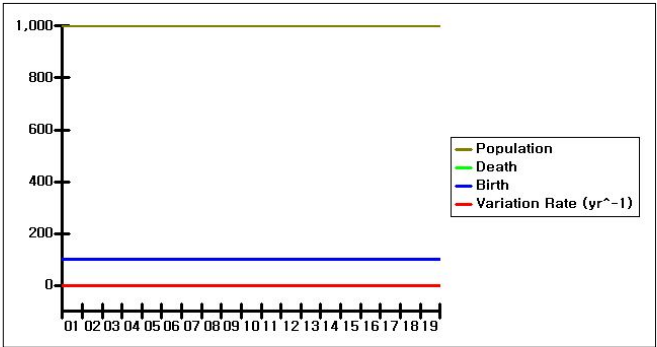

[Fig. 11] Simulated Result in the Condition 1

\subsubsection{Condition $2\left(B_{r}>D_{r}\right)$}

In the condition of $\mathrm{B}_{\mathrm{r}}>\mathrm{D}_{\mathrm{r}}$, values of all variables kept increasing during the simulation as shown in [Fig. 12]. So, the result with causal sequences of four variables in equation (3) and (4) could be defined as the CLD shown in [Fig. 13] which has two reinforcement(+) feedback loops(R1, R2).

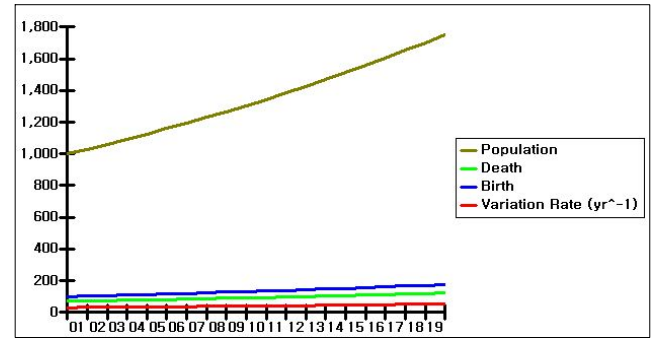

[Fig. 12] Simulated Result in the Condition 2

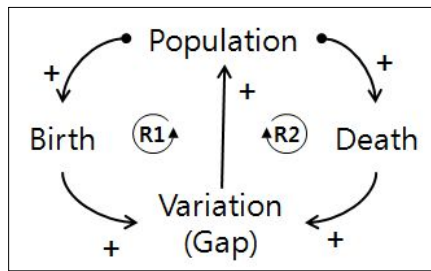

[Fig. 13] CLD under the Condition 2

\subsubsection{Condition3 $\left(B_{r}\left\langle D_{r}\right)\right.$}

In the condition of $\mathrm{B}_{\mathrm{r}}<\mathrm{D}_{\mathrm{r}}$, 'population', 'death' and 'birth' kept decreasing during the simulation but 'variation rate' increased with negative numbers as shown in [Fig. 14].

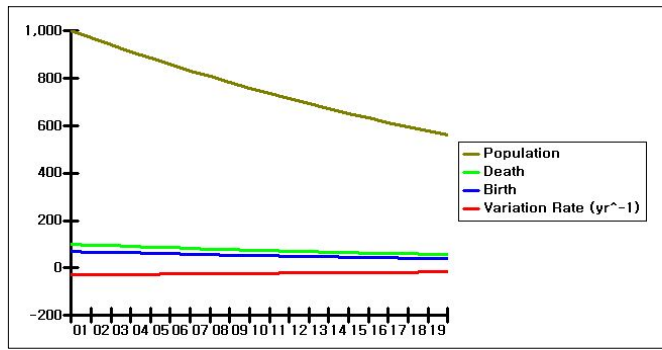

[Fig. 14] Simulated Result in the Condition 3 


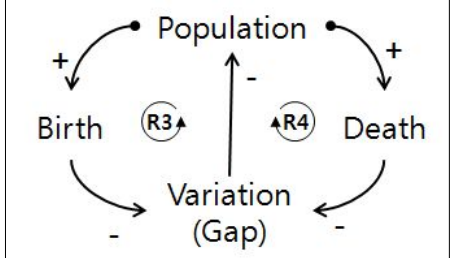

[Fig. 15] CDL under the Condition 3

[Fig. 15] was drawn from the dynamics of [Fig. 14]. Compared to [Fig. 13], it was the same in terms of system structure. Causal sequences and number of feedback loops overlapped exactly. Interestingly, though there were different pieces of causality between variables, those organized the same dominant feedback loops(R3, R4) with [Fig. 13].

\subsection{Coherence as a Strategy}

In the section 3 , we validated the flaws of the previous theories called 'reasoning a dominant feedback loop from the sigmoid(S-shaped growth) curve' and 'reasoning a shift of dominant feedback loops' on population dynamics in [Fig. 2] and in section 4, improved that by reinforcing and maintaining the coherence between CLD and SFD as shown in [Fig. $16]$.

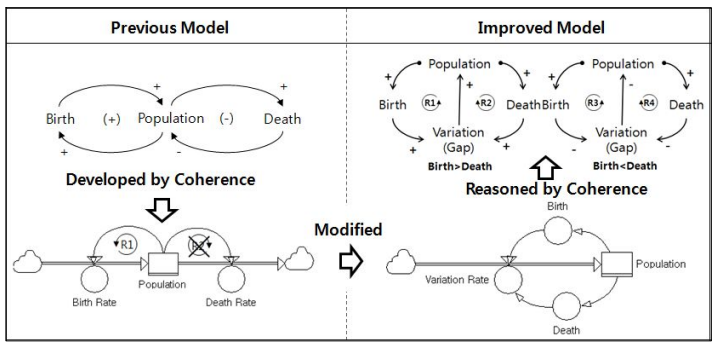

[Fig. 16] Processes for Improving the Existing Model

As a result, we found out the three conditional dynamics models which existed in the same structure for population dynamics. [Fig. 13] and [Fig. 15] could be defined as improved CLDs. Compared to [Fig. 2], the condition $2\left(\mathrm{~B}_{\mathrm{r}}>\mathrm{D}_{\mathrm{r}}\right)$ could be applied to the sigmoid growth curve. For improving this, we changed only $\mathrm{D}_{\mathrm{r}}$ on the condition 2 from $7 \%$ to $\left(\mathrm{P}_{\mathrm{t}-1} / 1000\right) \wedge$. The equation (5) expresses the number of the 'death' at time $t$

$$
D_{t}=\left(\frac{P_{t-1}}{1000}\right)^{n}
$$

Then, we simulated this condition and captured the sigmoid curve as shown in [Fig. 17] when $n$ was set at 7. Related to the power of ' $\mathrm{P}_{\mathrm{t}-1} / 100{ }^{\prime}$, the larger it was, the shorter the time to arrive at the end of the growth was.

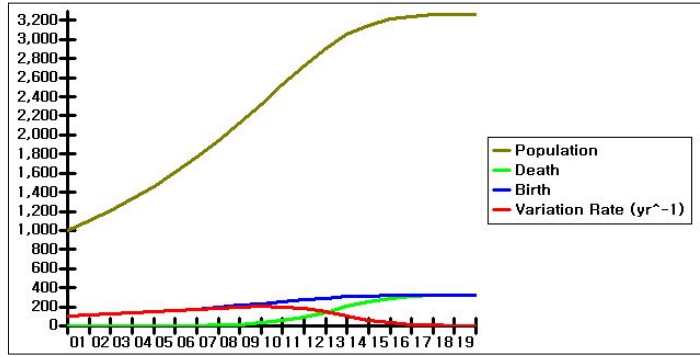

[Fig. 17] Another Dynamics S-Shaped

That result validated that the CLD of [Fig. 13] could be utilized to reason the sigmoid curve. Also it demonstrated that the 'variation (rate)' which was the gap between the 'birth' and 'death' determined differential coefficients of the population dynamics curve as shown in [Fig. 3]. However that does not mean circular causation can be inferred from the growth curve because the curve of 'variation (rate)' in [Fig. 17] shows an oscillation pattern different from that of [Fig. 12].

From this result, we found out that our improved model and coherence strategy were satisfied under the linear expressions

\section{Conclusion}

We raised a question about validity of the existing 
SD model and theory through the population dynamics model which was a representative SD model. The model was utilized to explain how to reason a dominant feedback loop and a shift between different dominant feedback loops as well as how to draw a CLD with feedback thinking.

For our question, we first conducted the simple proofs for the population dynamics model from the two viewpoints; geometrical characteristics of the sigmoid curve and validity of the CLD. As a result, the principle of reasoning from the sigmoid curve was not valid. In addition, the population dynamics CLD had the logical defects. Those confirmed that our doubt was rational. On the other hand, we improved the flawed CLD by strengthening the coherence between CLD and SFD. The improved CLD had validity under the condition that birth and death rates were linear, not exponential.

Our approaches and findings emphasize the importance of scientific verification for the existing SD theory(model). Also, they invigorate scientific discussion and theoretical improvements of SD for more robust application of the methodology.

\section{ACKNOWLEDGMENTS}

This work was supported by the National Research Foundation of Korea Grant funded by the Korean Government(NRF-2011-35C-B00111)

\section{REFERENCES}

[1] Forrester, Industrial Dynamics, MA: MIT Press, Reprinted by Pegasus, 1961.

[2] Forrester, Urban Dynamics, MA: MIT Press, Reprinted by Pegasus, 1969.

[3] Sterman, Business Dynamics-System Thinking and a Complex World, Boston: McGraw-Hill, 2000.

[4] Introduction to System Dynamics(http://www.syste

mdynamics.org/what-is-s)

[5] Kim, D. H., Systems Thinking, Seoul: Sunhaksa, 2006.

[6] Kim. D. H., Moon, T. H. and Kim, D. H., Sytem Dynamics, Soeul: Daeyoung MunWha Publishing Co., 2001.

[7] Richardson, Problem in Causal Loop Diagrams Revisited, System Dynamics Review, Vol. 13, No. 3, pp. 247-252, 1997.

[8] Jung, J. U. and Kim, H. S., A Study on Theoretical Improvement of Causal Mapping for Dynamic Analysis and Design, Korean System Dynamics Review, Vol. 10, No. 1, pp. 33-60, 2009.

[9] Jung, J. U. and Kim, H. S., A Study on Ensuring Validity and Increasing Power of Expression on Causal Maps, Korean System Dynamics Review, Vol. 8, No. 1, pp. 97-115, 2007.

\section{Jung, Jae Un(정 재 운)}

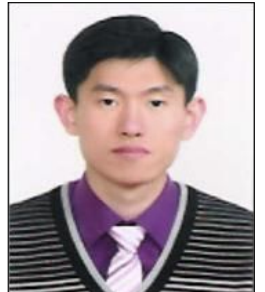

·Feb. 2008 : Dong-A University, M.S. in MIS

-Aug. 2010 : Dong-A University, Ph.D. in MIS - Oct. $2013 \sim$ : Dong-A University, BK21Plus Groups, Research Professor

- Research Area : Logistics Information System, System Dynamics, etc.

•E-Mail : imhere@dau.ac.kr

\section{Kim, Hyun Soo(김 현 수)}

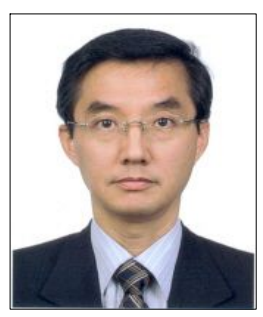

Information System, etc.

·E-Mail : hskim@dau.ac.kr

· Feb. 1987 : KAIST, M.S. in Management Science

- Feb. 1992 : KAIST, Ph.D. in Management Science

- Mar. 1992 : Dong-A University, Dept. of MIS, Professor

- Research Area: Logistics Information System, Intelligent 